\title{
Integrated microRNA-mRNA analyses of distinct expression profiles in follicular thyroid tumors
}

\author{
JIADONG CHI $^{1,2}$, XIANGQIAN ZHENG ${ }^{1}$, MING GAO $^{1}$, JINGZHU ZHAO ${ }^{1}$, \\ DAPENG LI ${ }^{1}$, JIANSEN LI ${ }^{1}$, LI DONG ${ }^{1}$ and XIANHUI RUAN ${ }^{1}$ \\ ${ }^{1}$ Department of Thyroid and Neck Tumors, Tianjin Medical University Cancer Institute and Hospital, \\ Oncology Key Laboratory of Cancer Prevention and Therapy, National Clinical Research Center of Cancer, \\ Tianjin 300060; ${ }^{2}$ Department of Graduate College, Tianjin Medical University, Tianjin 300070, P.R. China
}

Received June 28, 2016; Accepted August 10, 2017

DOI: $10.3892 / \mathrm{ol} .2017 .7146$

\begin{abstract}
MicroRNAs (miRNAs/miRs) are small non-coding RNAs identified in plants, animals and certain viruses; they function in RNA silencing and post-transcriptional regulation of gene expression. miRNAs also serve an important role in the pathogenesis, diagnosis and treatment of tumors. However, few studies have investigated the role of miRNAs in thyroid tumors. In the present study, the expression of miRNA and mRNA was compared between follicular thyroid carcinoma (FTC) and follicular thyroid adenoma (FA) samples, and then miRNA-mRNA regulatory network analysis was performed. Microarray datasets (GSE29315 and GSE62054) were downloaded from the Gene Expression Omnibus, and profiling data were processed with R software. Differentially expressed miRNAs (DEMs) and differentially expressed genes (DEGs) were determined, and Gene Ontology enrichment analysis was subsequently performed for DEGs using the Database for Annotation, Visualization and Integrated Discovery. The target genes of the DEMs were identified with miRWalk, miRecords and TarMir databases. Network analysis of the DEMs and DEMs-targeted DEGs was performed using Cytoscape software. In GSE62054, 23 downregulated and 9 upregulated miRNAs were identified. In GSE29315, 42 downregulated and 44 upregulated mRNAs were identified. A total of 36 miRNA-gene pairs were also identified. Network analysis indicated a co-regulatory association between miR-296-5p, miR-10a, miR-139-5p, miR-452, miR-493, miR-7, miR-137, miR-144, miR-145 and corresponding targeted mRNAs, including TNF receptor superfamily member $11 \mathrm{~b}$, benzodiazepine receptor (peripheral) -associated protein 1,
\end{abstract}

Correspondence to: Professor Ming Gao, Department of Thyroid and Neck Tumors, Tianjin Medical University Cancer Institute and Hospital, Oncology Key Laboratory of Cancer Prevention and Therapy, National Clinical Research Center of Cancer, 1 Huan Hu Xi Road, He Xi, Tianjin 300060, P.R. China

E-mail: headandneckgaoming@163.com

Key words: follicular thyroid tumors, differentially expressed miRNAs, differentially expressed mRNA, gene ontology enrichment analysis, network analysis and transforming growth factor $\beta$ receptor 2 . These results suggest that miRNA-mRNAs networks serve an important role in the pathogenesis, diagnosis and treatment of FTC and FA.

\section{Introduction}

Thyroid follicular cells are found in the thyroid gland, specifically in the epithelial monolayer. In total, $>95 \%$ of thyroid tumors are derived from these follicular cells (1). In 2016, the incidence of thyroid tumors rose globally, largely due to technological and diagnostic advances (2). However, it remains difficult to distinguish whether a thyroid nodule is benign or malignant. Follicular thyroid tumors may be divided into malignant follicular thyroid carcinoma (FTC) and benign follicular thyroid adenoma (FA). Only 5-10\% of thyroid nodules are malignant (3). Patients with follicular tumors usually must undergo thyroid lobectomy for diagnosis, which is often an unnecessary surgery, as the disease is usually benign. Fine-needle aspiration cytology is considered the most accurate method for the diagnosis of FTC and FA (4).

Previously, microRNAs (miRNAs/miRs) have been demonstrated to be involved in the pathogenesis of various diseases, like cancer, diabetes and osteoarthritis (5-7). miRNAs are small (18-25 nucleotides) non-coding, single-stranded RNA molecules that bind to targets in a base pair-mediated manner, resulting in the degradation or inhibition of the expression and function of protein-coding mRNAs. miRNAs often bind to the 3'-untranslated region (3'UTR) of target genes (8), although they are usually only partially complementary to the target (9). miRNAs regulate $\sim 30 \%$ of the human genes associated with proliferation, apoptosis, metastasis, cell immunity and differentiation (10). Each miRNA is able to regulate several hundred mRNAs, and each mRNA may be the target of several miRNAs. Therefore, a regulatory control network exists between miRNAs and mRNAs (11). Furthermore, miRNAs have been associated with several types of tumors, including non-small cell lung cancer, colon and esophageal cancer, and FTC (12-14). However, there are few studies of specific miRNA and mRNA analyses of follicular thyroid tumors. 
Several microarray studies have already described the differentially expressed genes (DEGs) between malignant and benign thyroid nodules. However, these studies have several restrictions, including the fact that the samples are limited, they contain significant false-negatives, and they require external analysis at an offsite company laboratory (15-17). Certain studies have aimed to reveal the potential miRNAs associated with follicular thyroid tumors (18).

In the present study, an integrated analysis of differentially expressed miRNAs (DEMs) and DEGs between FTC and FA was performed. A Gene Ontology (GO) analysis of the DEGs was performed. A total of 36 miRNA-gene pairs were identified between the DEGs and the target genes of the DEMs. A miRNA-mRNA network analysis was then performed to additionally investigate the pathogenesis of FTC.

\section{Materials and methods}

Analysis of $m R N A$ and miRNA profiling datasets. Expression profile datasets containing mRNA and miRNA were acquired from the Gene Expression Omnibus (GEO; http://www.ncbi. nlm.nih.gov/geo/). The expression profiling data of GSE29315 (Tomas et al, unpublished) are mRNA profiling data, originally obtained from a cohort of 9 FTC and 17 FA samples. The GSE62054 dataset contains miRNA profiling data, which was originally obtained from 17 FTC and 8 FA samples (19). Additionally, GSE29315 was hybridized on the Affymetrix U95 GeneChip platform (Affymetrix; ThermoFisher Scientific, Inc., Waltham, MA, USA) and GSE62054 was performed on the Illumina Human v2 miRNA expression BeadChip (Illumina, Inc., San Diego, CA, USA).

Preprocessing of profiling data. GSE29315 and GSE62054 data were first preprocessed by the Affy package in $\mathrm{R}$ language version 3.4.0 and then were processed by $\log _{2}$ transformation, background correction and data normalization using the Robust Multi-array Average algorithm (20).

Identification of DEMs, DEGs and GO enrichment analysis. Identification of DEMs and DEGs were conducted by the Limma package version 3.32.5 in R software (21). The threshold values for different expression were $\log _{2}$ (fold-change) $>0.5$ or $\log _{2}$ (fold-change) $<-0.5$ with $\mathrm{P}<0.05$ (22) GO enrichment analysis for DEGs was performed with the Database for Annotation, Visualization and Integrated Discovery (DAVID) (23).

Overlapping genes of DEGs and the predicted target genes of the DEMs. The predicted target mRNAs of the DEMs were generated using the miRWalk (24), miRecords (25) and TarMir databases (26). The overlapping DEGs and the predicted target mRNAs of the DEMs were identified for additional network analysis.

Construction and analysis of miRNA-mRNA regulatory network. To obtain an improved understanding of the biological function of the miRNA-mRNA regulatory network, node-degree analysis was performed, based on the overlapping genes and their upstream miRNAs. The network was visualized using the Cytoscape platform software version 3.0.1 (27).

\section{Results}

Identifying DEMS and DEGs between FTC and FA. GSE29315 and GSE62054 were downloaded from GEO and then normalized, and corrected by the quantile normalization method and hierarchical clustering analysis using R software. DEMs and DEGs were identified between the FTC and FA. A total of 86 DEGs and 32 DEMs were obtained when the threshold values were set at $\mathrm{P}<0.05$ and $\log _{2}$ (fold-change) $>0.5$ or $\log _{2}$ (fold-change) $<-0.5$. The top 5 downregulated DEMs were miR-7, miR-1179, miR-7-2, miR-486-5p and miR-130b. The top 5 upregulated DEMs were miR-663b, miR-137, miR-30c-1, miR-767-5p and miR-603 (Table I). As for the DEGs, the top 5 downregulated genes were fatty acid binding protein 4 (FABP4), cytidine monophospho-N-acetylneruaminic acid (CMAHP), integral membrane protein 2A (ITM2A), carbonic anhydrase 4 (CA4) and family with sequence similarity 189 member A2 (FAM189A2), and the top 5 upregulated genes were erythrocyte membrane protein band 4.1 like 3 (EPB41L3), secretogranin V (SCG5), paired box 1 (PAX1), methylenetetrahydrofolate dehydrogenase (NADP + dependent) 2, methenyltetrahydrofolate cyclohydrolase (MTHFD2) and cadherin 2 (CDH2) (Table II). A volcano plot was constructed to identify the DEGs (Fig. 1).

GO enrichment analysis of DEGs. GO analysis of all the DEGs (Table III) identified 8 associated biological processes: Positive regulation of macromolecule metabolic process, regulation of cell motion, cell proliferation, tube development, regulation of response to external stimulus, regulation of locomotion, response to drug and $\mathrm{T}$ cell activation (Fig. 2).

Integrated network analysis of miRNA-mRNA interaction. From the miRWalk, miRecords and TarMir databases, target genes of the DEMs were identified. A total of 24 overlapping genes were identified between the targets genes and DEGs (Table IV). Furthermore, 36 miRNA-gene pairs were obtained among the 24 overlapping genes and 9 DEMs (Table V). Node-degree analysis is summarized in Table VI. The regulation network between those overlapping genes and their upstream miRNAs is presented in Fig. 3.

\section{Discussion}

The important roles of miRNAs in the pathogenesis of FTC have been identified previously (28). miRNAs exhibit different expression patterns within different tumor types, and are closely associated with the diagnosis, treatment and prognosis of tumors (29-31). Ak et al (21) observed that DEMs and differentially expressed mRNAs vary between benign and malignant tumors, which may suggest the different roles of these miRNAs and mRNAs. miR-197 and miR-346 have been indicated to be overexpressed in FTC, resulting in the dysregulation of their target genes (32). However, studies regarding DEMs and DEGs in FTC are rare. In the present study, the difference between miRNA-mRNA regulatory networks from FTC and FA samples were compared in order to investigate the mechanism of FTC. It was identified that miR-7, miR-1179, miR-7-2, miR-486-5p and miR-130b were the top downregulated miRNAs, and that miR-663b, miR-137, 
Table I. Top 5 differentially expressed miRNAs of malignant follicular thyroid carcinoma compared with benign follicular thyroid adenoma.

\begin{tabular}{lcc}
\hline miRNA & P-value & $\log _{2}$ (fold-change) \\
\hline $\begin{array}{l}\text { Downregulated } \\
\text { miR-7 }\end{array}$ & & \\
miR-1179 & 0.0041392 & -1.7320437 \\
miR-7-2 & 0.0081728 & -1.3950195 \\
miR-486-5p & 0.0006626 & -1.2525509 \\
miR-130b & 0.0412501 & -1.0502825 \\
Upregulated & 0.0028172 & -0.9176468 \\
miR-663b & & \\
miR-137 & 0.0009353 & 0.9881272 \\
miR-30c-1 & 0.0088044 & 0.9341108 \\
miR-767-5p & 0.0059237 & 0.8695624 \\
miR-603 & 0.0036048 & 0.7353497 \\
\hline
\end{tabular}

miR/miRNA, microRNA.

Table II. Top 5 differentially expressed mRNAs of malignant follicular thyroid carcinoma compared with benign follicular thyroid adenoma.

\begin{tabular}{lcc}
\hline mRNA & P-value & $\log _{2}$ (fold-change) \\
\hline $\begin{array}{l}\text { Downregulated } \\
\text { FABP4 }\end{array}$ & 0.001621719 & -2.100023748 \\
CMAHP & 0.024414059 & -1.066127774 \\
ITM2A & 0.016922069 & -1.060957028 \\
CA4 & 0.003105875 & -1.030691864 \\
FAM189A2 & 0.001993414 & -1.000814956 \\
Upregulated & & \\
EPB41L3 & 0.000527208 & 1.020917517 \\
SCG5 & 0.044745635 & 0.990761798 \\
PAX1 & 0.040281329 & 0.936795356 \\
MTHFD2 & 0.002917107 & 0.870767506 \\
CDH2 & 0.038829964 & 0.862357097 \\
\hline
\end{tabular}

miR-30c-1, miR-767-5p and miR-603 were the top upregulated miRNAs. For the DEGs, the top downregulated genes were FABP4, CMAHP, ITM2A, CA4 and FAM189A2, and the top upregulated genes were EPB41L3, SCG5, PAX1, MTHFD2 and $\mathrm{CDH} 2$. In addition, miR-7, miR-296-5p, miR-10a, miR-144, miR-139-5p, miR-452 and miR-145 were downregulated, and miR-137 and miR-493 were upregulated in the FTC miRNA-mRNA regulatory network compared with those in FA. The gene arrays identified DEGs, in which leucine rich repeat neuronal 3, chromodomain helicase DNA binding protein 9, PKIA, zinc finger protein 148 (ZNF148), TGFB induced factor homeobox 1 , transforming growth factor $\beta$ receptor 2, gap junction protein $\alpha 1$ and $\mathrm{CDH} 2$ were observed to be target genes inversely correlated with miR-7, miR-144,

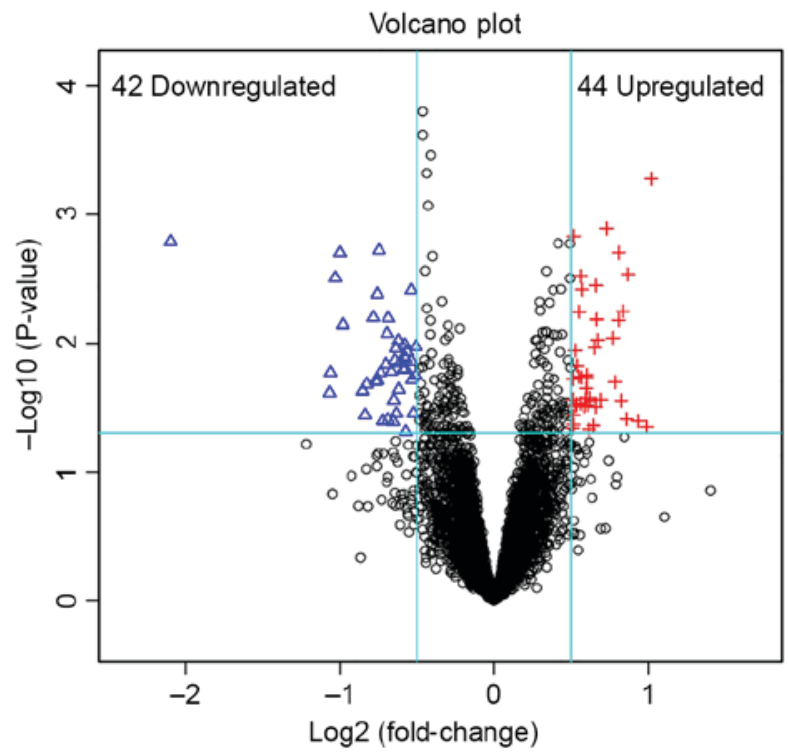

Figure 1. Distribution of differentially expressed genes between the malignant and benign follicular thyroid tumors in GSE29315. Blue triangles indicate 42 significantly downregulated genes and red crosses indicate 44 significantly upregulated genes.

miR-139-5p, miR-145 and miR-137. In other studies, FTC or FA have been compared with normal tissue, and differences in miRNA expression were observed to occur in the range between 1.2- and 2-fold, which was similar to the data of the present study (33-35).

In the present study, it was identified that miR-7, miR-296-5p, miR-10a, miR-144, miR-139-5p, miR-452, miR-145, miR-137 and miR-493 are important miRNAs that are differentially expressed between carcinoma and adenoma samples. Certain studies have suggested that miR-7 is not only a tumor promoter, but also a tumor suppressor. As a tumor suppressor, miR-7 is downregulated in tumors, such as thyroid cancer, breast cancer and castration-resistant prostate cancer, leading to a derepression of the oncogenes epidermal growth factor receptor, insulin receptor substrate 1, Raf-1 proto-oncogene, serine/threonine kinase, tyrosine kinase non-receptor 2, phosphatidylinositol-4,5-bisphosphate 3 -kinase catalytic subunit $\delta$, mechanistic target of rapamycin kinase, Ribosomal protein S6 kinase $\beta-1$ and phosphatidylinositol-4,5-bisphosphate 3-kinase (36-38). miR-296-5p has been revealed to be significantly inversely correlated with post-contrast $\mathrm{T} 1$ values for diffuse myocardial fibrosis in patients with hypertrophic cardiomyopathy, and is a downstream effector under conditions that promote glioblastoma stem cell stemness, and inhibit glioblastoma cell stemness and their capacity to self-renew as spheres and propagate glioma xenografts in vivo $(39,40)$. miR-10a has been identified as a downregulated miRNA associated with human metastatic medullary thyroid carcinoma, and it may be important for tumor development and/or reflect C-cell lineage $(41,42)$. miR-144 may suppress the invasion and migration capability of thyroid cancer and suppress the expression of zinc finger E-box-binding homeobox (ZEB)1 and ZEB2, the two E-cadherin suppressors, by directly binding their 3'UTRs (43). miR-137 was indicated to participate in hematopoiesis, particularly in the efficacy 
Table III. Differentially expressed mRNAs of malignant follicular thyroid carcinoma compared with benign follicular thyroid adenoma.

\begin{tabular}{|c|c|c|}
\hline Gene & P-value & $\log _{2}$ (fold-change) \\
\hline FABP4 & 0.001621719 & -2.100023748 \\
\hline СМАНР & 0.024414059 & -1.066127776 \\
\hline ITM2A & 0.016922069 & -1.060957028 \\
\hline CA4 & 0.003105875 & -1.030691864 \\
\hline FAM189A2 & 0.001993414 & -1.000814956 \\
\hline MPPED2 & 0.007206792 & -0.981309728 \\
\hline HGD & 0.023615869 & -0.852452356 \\
\hline TNFRSF11B & 0.036234193 & -0.836887107 \\
\hline SLC16A4 & 0.020876545 & -0.826437495 \\
\hline BZRAP1 & 0.006323889 & -0.784389089 \\
\hline PDGFRL & 0.019724555 & -0.769696713 \\
\hline TFF3 & 0.004160978 & -0.758375163 \\
\hline LAMB1 & 0.019590536 & -0.754903323 \\
\hline UBR2 & 0.001897906 & -0.746515077 \\
\hline TGFBR2 & 0.016942031 & -0.736954014 \\
\hline CPQ & 0.040123761 & -0.722559518 \\
\hline RDX & 0.014625862 & -0.700582583 \\
\hline PTPRN2 & 0.008418827 & -0.692563257 \\
\hline SALL1 & 0.039302461 & -0.687132893 \\
\hline LRRN3 & 0.006382367 & -0.685656353 \\
\hline TRAM2 & 0.016638751 & -0.664343953 \\
\hline SLITRK5 & 0.040721395 & -0.652918137 \\
\hline RGS16 & 0.027819411 & -0.648828034 \\
\hline STARD13 & 0.013643606 & -0.642603503 \\
\hline THBD & 0.010984131 & -0.635676793 \\
\hline GJA1 & 0.035287842 & -0.633044868 \\
\hline TNFSF10 & 0.009577025 & -0.620052341 \\
\hline PKIA & 0.022943634 & -0.617442203 \\
\hline CLDN8 & 0.014099121 & -0.606720582 \\
\hline IL11RA & 0.016027339 & -0.589253369 \\
\hline CDC27 & 0.012718038 & -0.584208837 \\
\hline SLC35D2 & 0.010299633 & -0.579905832 \\
\hline IFI44L & 0.015727697 & -0.576791484 \\
\hline NR2F2 & 0.013187137 & -0.575425266 \\
\hline CHD9 & 0.048840737 & -0.573993055 \\
\hline FCGRT & 0.011662768 & -0.566086321 \\
\hline AGTR1 & 0.013773676 & -0.538397573 \\
\hline CXCL12 & 0.003888448 & -0.538189987 \\
\hline HSD17B8 & 0.019222754 & -0.533271237 \\
\hline LOC728093 & 0.035060908 & -0.524392385 \\
\hline SELE & 0.017742851 & -0.507241011 \\
\hline AKAP12 & 0.010628133 & -0.506141506 \\
\hline PVALB & 0.045712444 & 0.509393237 \\
\hline NNT & 0.027397598 & 0.513526356 \\
\hline ADORA1 & 0.036372247 & 0.513841883 \\
\hline GPI & 0.018981531 & 0.514219746 \\
\hline AREG & 0.042790083 & 0.515091119 \\
\hline ELF4 & 0.001468499 & 0.516939945 \\
\hline NAB2 & 0.011359365 & 0.527142113 \\
\hline GPC1 & 0.030827537 & 0.529427807 \\
\hline
\end{tabular}

Table III. Continued.

\begin{tabular}{lcc}
\hline Gene & P-value & $\log _{2}$ (fold-change) \\
\hline SLC25A5 & 0.029858761 & 0.534298394 \\
RYR1 & 0.014981235 & 0.538436907 \\
PEG10 & 0.018255692 & 0.549699307 \\
SLIT2 & 0.005701378 & 0.551929669 \\
ESYT1 & 0.003009396 & 0.561757654 \\
CRLF1 & 0.029356956 & 0.562850973 \\
DPP4 & 0.018431425 & 0.567301902 \\
CES2 & 0.003842477 & 0.571035541 \\
CYCS & 0.030715945 & 0.585863898 \\
BASP1 & 0.026758782 & 0.594217929 \\
KLHL21 & 0.022505203 & 0.599053201 \\
LCN2 & 0.017669691 & 0.601124995 \\
EEF1A2 & 0.018392179 & 0.602560272 \\
TGIF1 & 0.030147532 & 0.605396529 \\
TSPYL2 & 0.046736047 & 0.617648983 \\
CKS2 & 0.026759687 & 0.623716633 \\
SPAG5 & 0.027923235 & 0.624868361 \\
CKMT2 & 0.043578063 & 0.645621487 \\
ALDH1A3 & 0.010848438 & 0.653685247 \\
ZNF148 & 0.031227695 & 0.661077991 \\
UCHL1 & 0.003566593 & 0.663217388 \\
ASNS & 0.006539605 & 0.667304137 \\
NPTXR & 0.009448284 & 0.674187256 \\
FKBP5 & 0.027541727 & 0.694255151 \\
GOT1 & 0.001282557 & 0.730143285 \\
IGFBP3 & 0.009116606 & 0.771327366 \\
SERPINE2 & 0.020069598 & 0.785032654 \\
SOX4 & 0.006616428 & 0.808876177 \\
BSG & 0.001981905 & 0.809699733 \\
SCNN1A & 0.027983691 & 0.825462627 \\
NPC2 & 0.005654992 & 0.837641446 \\
CDH2 & 0.038829964 & 0.862357097 \\
MTHFD2 & 0.002917107 & 0.870767506 \\
PAX1 & 0.040281329 & 0.936795356 \\
SCG5 & 0.044745635 & 0.990761798 \\
EPB41L3 & 0.000527208 & 1.020917517 \\
\hline
\end{tabular}

of warfarin, wherein miR-137 may cause aberrant vitamin $\mathrm{K}$ epoxide reductase complex subunit 1 expression (44). miR-139-5p is an oncogenic molecule in the process of tumorigenesis, and has been demonstrated to be a sensitive and specific biomarker for the diagnosis of thyroid tumors and others tumor types (45). Furthermore, it may be of use as a tractable therapeutic target to decrease the mortality rate and increase the survival rate (46). miR-145 has primarily been indicated as being downregulated in colorectal tumors. Previously, certain studies have identified that miR-145 is highly expressed in mesenchymal cells such as fibroblasts and smooth muscle cells (47). The miRNA was demonstrated to directly regulate the expression of thyroid hormone receptor TR $\beta 1$ in renal cancer cells and to correlate with intracellular 


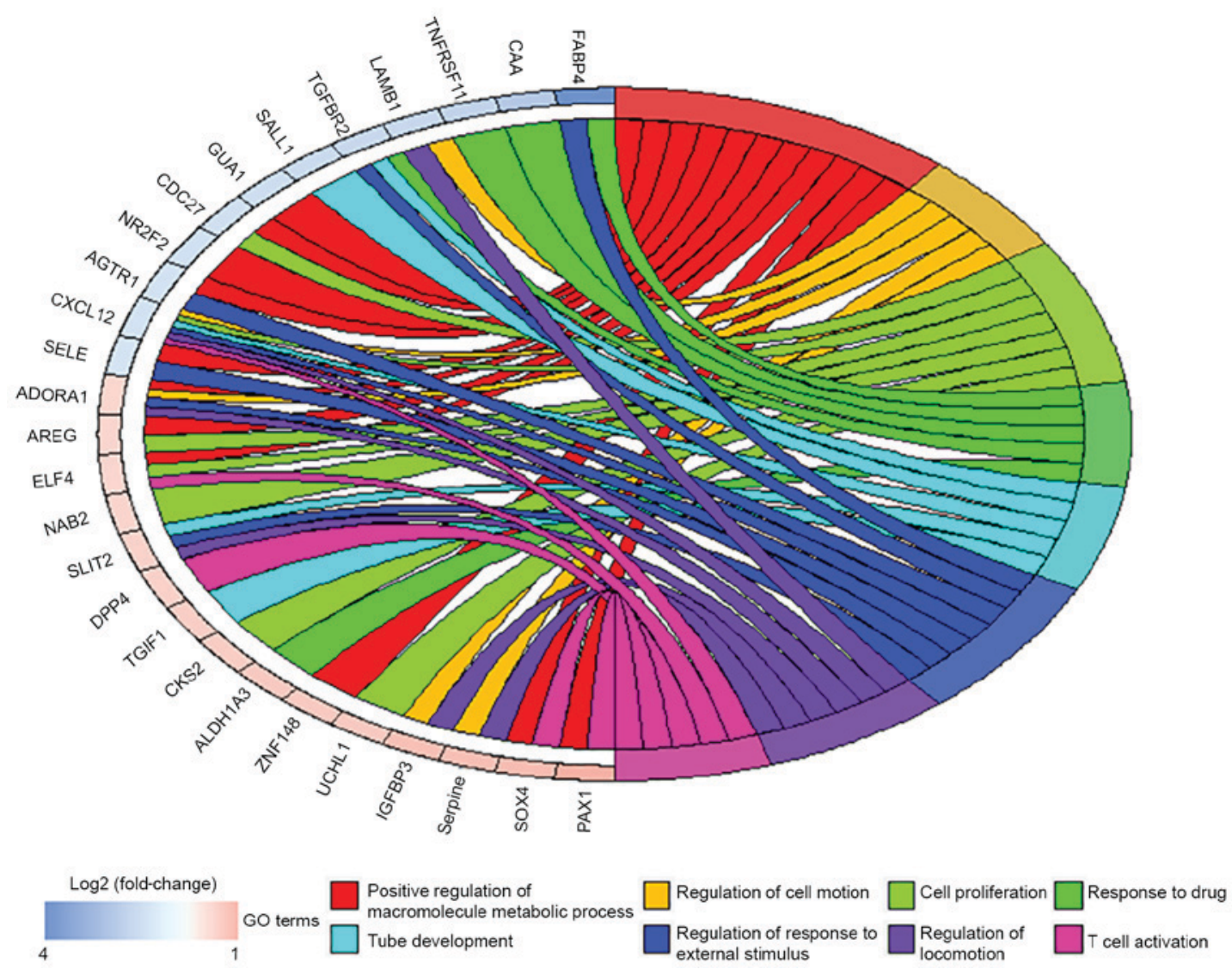

Figure 2. GO analysis of differentially expressed genes between malignant and benign follicular thyroid tumors in GSE29315. GO, Gene Ontology.

triiodothyronine concentrations in renal tumors (48). miR-493 also promoted the invasion and chemoresistance of gastric cancer cells. However, dickkopf related-protein 1 overexpression reversed its effects on proliferation, invasion and chemo-sensitivity (49). Based on these data, we hypothesize that these miRNAs serve important roles in FTC with different pathways.

In the present study, several genes that were overlapping were identified between the DEGs and the target genes of the DEMs. These may be upregulated or downregulated. However, they all contributed to the development of FTC. Certain functions of these genes in cancer have been studied. For example, ZNF148 is a member of the human zinc finger Krüppel family and it maps to regions implicated in recurrent chromosomal rearrangements in hematological malignancies (50). The present study identified spalt-like transcription factor 1 (SALL1), which is one of the four human family members of the Spalt family. Members of the Spalt family are highly conserved zinc-finger transcription factors that are conserved from Caenorhabditis elegans to vertebrates, with regulatory functions in organogenesis, limb formation and cell fate assignment during neural development. SALL1 expression has been identified to correlate with the expression of $\mathrm{CDH} 1$, which is consistent with its tumor suppressive function and suggests its potential involvement in epithelial-to-mesenchymal transition $(51,52)$. Cell division cycle 27 (CDC27) is a core component of the anaphase-promoting complex and is involved in the regulation of mitotic checkpoints to ensure chromosomal integrity (53). CDC27 may significantly affect the function of the polymeric protein complex and is also a target of certain anticancer drugs $(54,55)$. Nuclear receptor subfamily 2 group F member 2 (NR2F2), also known as chicken ovalbumin upstream promoter transcription factor, is highly prioritized as a candidate gene associated with hypertension (56). Certain studies have demonstrated that NR2F2 is nuclear receptor transcription factor vital for angiogenesis and heart development (57). These data suggest that several genes have functions in numerous pathways involved in tumorigenesis and progression.

Each miRNA is able to regulate several hundred mRNAs. In addition, each mRNA may be targeted by several miRNAs and each mRNA participates in several biological functions in the human body. Therefore, each miRNA may affect different biological processes and pathways through a miRNA-mRNA network $(58,59)$. It is important to understand the pathogenesis and treatment of tumors by investigating the specific miRNA-mRNA co-regulation effects. In the present study, mRNAs and their functions were described with GO enrichment analysis. There were 86 mRNAs and 8 biological functions involved. In total, $\sim 80 \%$ of follicular carcinomas contain Ras gene mutations or a paired box gene 8/peroxisome proliferator-activated receptor $\gamma$ gene rearrangement, which leads to uncontrolled proliferation. Mutations in the phosphatase and tensin homologue suppressor gene and the phosphatidylinositol 3-kinase pathway may be an important factor in the development of more aggressive thyroid cancer types and may be more common in follicular cancer, which is responsible for cell motility, locomotion and response to 
Table IV. Significant regulation of mRNAs in the specific miRNA-mRNA interacting regulatory network.

\begin{tabular}{llc}
\hline Gene & P-value & $\log _{2}$ (fold-change) \\
\hline TNFRSF11B & 0.036234 & -0.836892 \\
BZRAP1 & 0.006324 & -0.784391 \\
TGFBR2 & 0.016942 & -0.736951 \\
SALL1 & 0.039302 & -0.687134 \\
LRRN3 & 0.006382 & -0.685662 \\
TRAM2 & 0.016639 & -0.664343 \\
RGS16 & 0.027819 & -0.648836 \\
STARD13 & 0.013644 & -0.642635 \\
THBD & 0.010984 & -0.635682 \\
GJA1 & 0.035288 & -0.633043 \\
PKIA & 0.022944 & -0.617443 \\
CDC27 & 0.012718 & -0.584214 \\
NR2F2 & 0.013187 & -0.575433 \\
CHD9 & 0.048841 & -0.573992 \\
CXCL12 & 0.003888 & -0.538192 \\
NAB2 & 0.011359 & 0.527142 \\
SLC25A5 & 0.029859 & 0.534298 \\
PEG10 & 0.018256 & 0.549699 \\
SLIT2 & 0.005701 & 0.551934 \\
BASP1 & 0.026759 & 0.594218 \\
TGIF1 & 0.030148 & 0.605397 \\
ALDH1A3 & 0.010848 & 0.653685 \\
ZNF148 & 0.031228 & 0.661078 \\
CDH2 & 0.038832 & 0.862357 \\
\hline & & \\
\hline
\end{tabular}

miRNA, microRNA.

Table V. Significant regulation of miRNAs in the specific miRNA-mRNA interacting regulatory network.

\begin{tabular}{llc}
\hline miRNA & P-value & $\log _{2}$ (fold-change) \\
\hline miR-7 & 0.0041392 & -1.7320437 \\
miR-137 & 0.0088043 & 0.9341108 \\
miR-144 & 0.0059723 & -0.8403724 \\
miR-139-5p & 0.0147834 & -0.5824534 \\
miR-145 & 0.0087553 & -0.5871226 \\
miR-296-5p & 0.0124989 & -0.5545413 \\
miR-10a & 0.0061396 & -0.7961598 \\
miR-452 & 0.0325921 & -0.5399825 \\
miR-493 & 0.0186862 & 0.6062014
\end{tabular}

miR/miRNA, microRNA.

external stimulus (60-62). Other factors that have been implicated in the pathogenesis of FTC include gene mutations in p53, c-myc, c-fos and the thyrotropin receptor (63-66). These molecules serve functions in cell proliferation, apoptosis, cytoskeleton rearrangement and responses to drugs. Additionally,
Table VI. Node-degree analysis of miRNA-mRNA interactions.

\begin{tabular}{lc}
\hline Node & Degree \\
\hline miR-144 & 10 \\
miR-137 & 9 \\
miR-145 & 5 \\
miR-7 & 5 \\
ZNF148 & 4 \\
miR-139-5p & 4 \\
PKIA & 3 \\
TGFBR2 & 3 \\
TRAM2 & 3 \\
TGIF1 & 3 \\
\hline
\end{tabular}

$\mathrm{miR} / \mathrm{miRNA}$, microRNA.

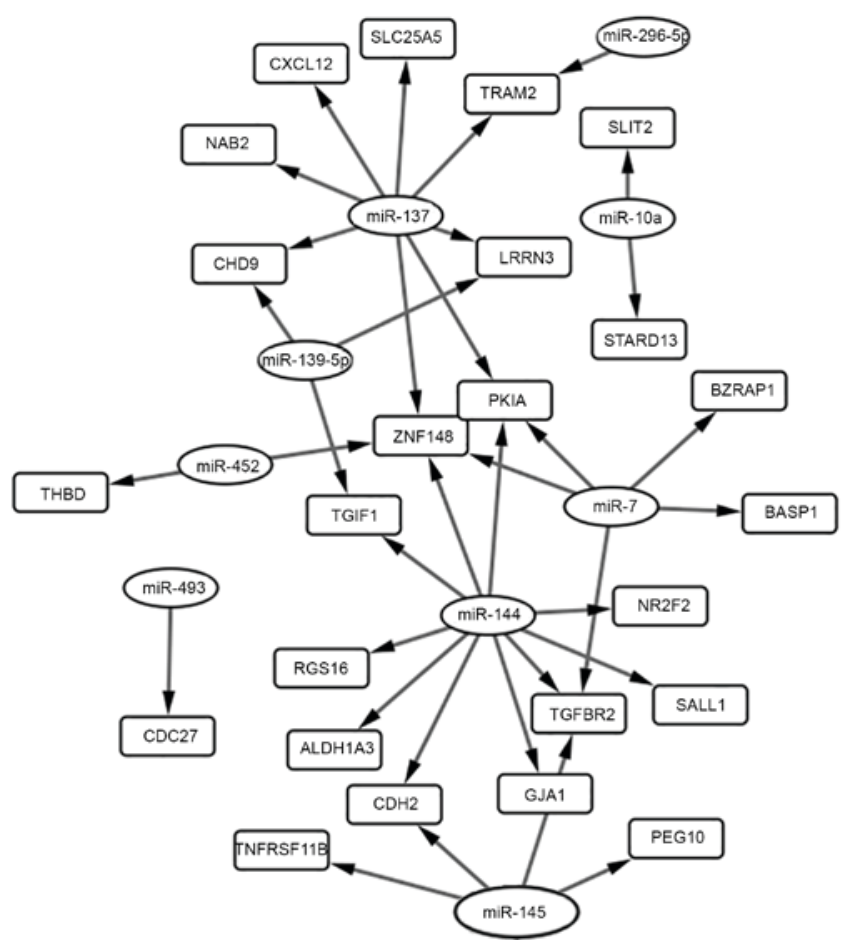

Figure 3. Regulatory network between miRNAs and their target mRNAs. miRNAs/miRs, microRNAs.

FTC, but not adenoma, recruits tumor-associated macrophages by releasing Chemokine (C-C motif) ligand 5; therefore, an abnormal immune response, including $\mathrm{T}$ cell activation, may be involved in follicular cancer. Other GO terms may be validated in future studies $(3,67)$.

In conclusion, the present study identified 86 DEGs and 32 DEMs between FTC and FA. A total of 24 overlapping genes were identified between the DEGs and the target genes of the DEMs. Network analysis indicated a co-regulatory association between miR-296-5p, miR-10a, miR-139-5p, miR-452, miR-493, miR-7, miR-137, miR-144, miR-145 and corresponding targeted mRNAs in FTC. However, the present study has limitations, such as the small sample size, although 
attention was paid to ensure the use of two genetically homogenous populations to avoid population stratification. The mechanism of the miRNA-mRNA network and the roles of these genes in FTC require additional study and validation in vitro and in vivo.

\section{References}

1. Kondo T, Ezzat S and Asa SL: Pathogenetic mechanisms in thyroid follicular-cell neoplasia. Nat Rev Cancer 6: 292-306, 2006.

2. Enewold L, Zhu K, Ron E, Marrogi AJ, Stojadinovic A, Peoples GE and Devesa SS: Rising thyroid cancer incidence in the United States by demographic and tumor characteristics, 1980-2005. Cancer Epidemiol Biomarkers Prev 18: 784-791, 2009.

3. McHenry CR and Phitayakorn R: Follicular adenoma and carcinoma of the thyroid gland. Oncologist 16: 585-593, 2011.

4. Francis GL, Waguespack SG, Bauer AJ, Angelos P, Benvenga S, Cerutti JM, Dinauer CA, Hamilton J, Hay ID, Luster M, et al: Management guidelines for children with thyroid nodules and differentiated thyroid cancer. Thyroid 25: 716-759, 2015.

5. Macfarlane LA and Murphy PR: MicroRNA: Biogenesis, function and role in cancer. Curr Genomics 11: 537-561, 2010.

6. Yu C, Chen WP and Wang XH: MicroRNA in osteoarthritis. J Int Med Res 39: 1-9, 2011

7. Wang C, Wan S, Yang T, Niu D, Zhang A, Yang C, Cai J, Wu J, Song J, Zhang CY, et al: Increased serum microRNAs are closely associated with the presence of microvascular complications in type 2 diabetes mellitus. Sci Rep 6: 20032, 2016.

8. Ambros V: The functions of animal microRNAs. Nature 431: 350-355, 2004.

9. Bartel DP: MicroRNAs: Genomics, biogenesis, mechanism, and function. Cell 116: 281-297, 2004.

10. Croce CM and Calin GA: miRNAs, cancer, and stem cell division. Cell 122: 6-7, 2005.

11. Chiang HR, Schoenfeld LW, Ruby JG, Auyeung VC, Spies N, Baek D, Johnston WK, Russ C, Luo S, Babiarz JE, et al: Mammalian microRNAs: Experimental evaluation of novel and previously annotated genes. Genes Dev 24: 992-1009, 2010.

12. Lu J, Getz G, Miska EA, Alvarez-Saavedra E, Lamb J, Peck D, Sweet-Cordero A, Ebert BL, Mak RH, Ferrando AA, et al: MicroRNA expression profiles classify human cancers. Nature 435: 834-838, 2005.

13. Hu Z, Chen X, Zhao Y, Tian T, Jin G, Shu Y, Chen Y, Xu L, Zen $\mathrm{K}$, Zhang $\mathrm{C}$ and Shen H: Serum microRNA signatures identified in a genome-wide serum microRNA expression profiling predict survival of non-small-cell lung cancer. J Clin Oncol 28: 1721-1726, 2010.

14. Ji J, Shi J, Budhu A, Yu Z, Forgues M, Roessler S, Ambs S, Chen Y, Meltzer PS, Croce CM, et al: MicroRNA expression, survival, and response to interferon in liver cancer. $\mathrm{N}$ Engl J Med 361: 1437-1447, 2009.

15. Finley DJ, Zhu B, Barden CB and Fahey TJ III: Discrimination of benign and malignant thyroid nodules by molecular profiling. Ann Surg 240: 425-437, 2004.

16. Barden CB, Shister KW, Zhu B, Guiter G, Greenblatt DY, Zeiger MA and Fahey TJ III: Classification of follicular thyroid tumors by molecular signature: Results of gene profiling. Clin Cancer Res 9: 1792-1800, 2003.

17. Aldred MA, Huang Y, Liyanarachchi S, Pellegata NS, Gimm O, Jhiang S, Davuluri RV, de la Chapelle A and Eng C: Papillary and follicular thyroid carcinomas show distinctly different microarray expression profiles and can be distinguished by a minimum of five genes. J Clin Oncol 22: 3531-3539, 2004.

18. de la Chapelle A and Jazdzewski K: MicroRNAs in thyroid cancer. J Clin Endocrinol Metab 96: 3326-3336, 2011.

19. Stokowy T, Wojtaś B, Krajewska J, Stobiecka E, Dralle H, Musholt T, Hauptmann S, Lange D, Hegedüs L, Jarząb B, et al: A two miRNA classifier differentiates follicular thyroid carcinomas from follicular thyroid adenomas. Mol Cell Endocrinol 399: 43-49, 2015.

20. Irizarry RA, Hobbs B, Collin F, Beazer-Barclay YD, Antonellis KJ, Scherf U and Speed TP: Exploration, normalization, and summaries of high density oligonucleotide array probe level data. Biostatistics 4: 249-264, 2003.
21. Ak G, Tomaszek SC, Kosari F, Metintas M, Jett JR, Metintas S, Yildirim H, Dundar E, Dong J, Aubry MC, Wigle DA and Thomas CF Jr: MicroRNA and mRNA features of malignant pleural mesothelioma and benign asbestos-related pleural effusion. Biomed Res Int 635748, 2015

22. Liu MY, Zhang H, Hu YJ, Chen YW and Zhao XN: Identification of key genes associated with cervical cancer by comprehensive analysis of transcriptome microarray and methylation microarray. Oncol Lett 12: 473-478, 2016.

23. Huang da W, Sherman BT and Lempicki RA: Systematic and integrative analysis of large gene lists using DAVID bioinformatics resources. Nat Protoc 4: 44-57, 2009.

24. Dweep H, Sticht C, Pandey P and Gretz N: miRWalk-database: Prediction of possible miRNA binding sites by 'walking' the genes of three genomes. J Biomed Inform 44: 839-847, 2011.

25. Xiao F, Zuo Z, Cai G, Kang S, Gao X and Li T: miRecords: An integrated resource for microRNA-target interactions. Nucleic Acids Res 37 (Database issue): D105-D110, 2009.

26. Liu PF, Jiang WH, Han YT, He LF, Zhang HL and Ren H: Integrated microRNA-mRNA analysis of pancreatic ductal adenocarcinoma. Genet Mol Res 14: 10288-10297, 2015.

27. Yeung N, Cline MS, Kuchinsky A, Smoot ME, Bader GD: Exploring biological networks with Cytoscape software. Curr Protoc Bioinformatics Chapter 8: Unit 8.13, 2008.

28. Stokowy T, Wojtas B, Jarzab B, Krohn K, Fredman D, Dralle H, Musholt T, Hauptmann S, Lange D, Hegedüs L, et al: Two-miRNA classifiers differentiate mutation-negative follicular thyroid carcinomas and follicular thyroid adenomas in fine needle aspirations with high specificity. Endocrine 54: 440-447, 2016.

29. Cerutti JM, Delcelo R, Amadei MJ, Nakabashi C, Maciel RM, Peterson B, Shoemaker J and Riggins GJ: A preoperative diagnostic test that distinguishes benign from malignant thyroid carcinoma based on gene expression. J Clin Invest 113: 1234-1242, 2004.

30. Umbricht CB, Conrad GT, Clark DP, Westra WH, Smith DC, Zahurak M, Saji M, Smallridge RC, Goodman S and Zeiger MA: Human telomerase reverse transcriptase gene expression and the surgical management of suspicious thyroid tumors. Clin Cancer Res 10: 5762-5768, 2004

31. Weber F, Shen L, Aldred MA, Morrison CD, Frilling A, Saji M, Schuppert F, Broelsch CE, Ringel MD and Eng C: Genetic classification of benign and malignant thyroid follicular neoplasia based on a three-gene combination. J Clin Endocrinol Metab 90: 2512-2521, 2005

32. Weber F, Teresi RE, Broelsch CE, Frilling A and Eng C: A limited set of human MicroRNA is deregulated in follicular thyroid carcinoma. J Clin Endocrinol Metab 91: 3584-3591, 2006.

33. Iorio MV, Ferracin M, Liu CG, Veronese A, Spizzo R, Sabbioni S, Magri E, Pedriali M, Fabbri M, Campiglio M, et al: MicroRNA gene expression deregulation in human breast cancer. Cancer Res 65: 7065-7070, 2005

34. Murakami Y, Yasuda T, Saigo K, Urashima T, Toyoda H, Okanoue $\mathrm{T}$ and Shimotohno K: Comprehensive analysis of microRNA expression patterns in hepatocellular carcinoma and non-tumorous tissues. Oncogene 25: 2537-2545, 2006.

35. He H, Jazdzewski K, Li W, Liyanarachchi S, Nagy R, Volinia S, Calin GA, Liu CG, Franssila K, Suster S, et al: The role of microRNA genes in papillary thyroid carcinoma. Proc Natl Acad Sci USA 102: 19075-19080, 2005.

36. Fang Y, Xue JL, Shen Q, Chen J and Tian L: MicroRNA-7 inhibits tumor growth and metastasis by targeting the phosphoinositide 3-kinase/Akt pathway in hepatocellular carcinoma. Hepatology 55: 1852-1862, 2012.

37. Jiang L, Liu X, Chen Z, Jin Y, Heidbreder CE, Kolokythas A, Wang A, Dai Y and Zhou X: MicroRNA-7 targets IGF1R (insulin-like growth factor 1 receptor) in tongue squamous cell carcinoma cells. Biochem J 432: 199-205, 2010

38. Reddy SD, Ohshiro K, Rayala SK and Kumar R: MicroRNA-7, a homeobox D10 target, inhibits p21-activated kinase 1 and regulates its functions. Cancer Res 68: 8195-8200, 2008.

39. Fang L, Ellims AH, Moore XL, White DA, Taylor AJ, Chin-Dusting $J$ and Dart AM: Circulating microRNAs as biomarkers for diffuse myocardial fibrosis in patients with hypertrophic cardiomyopathy. J Transl Med 13: 314, 2015.

40. Lopez-Bertoni H, Lal B, Michelson N, Guerrero-Cázares H, Quiñones-Hinojosa A, Li Y and Laterra J: Epigenetic modulation of a miR-296-5p:HMGA1 axis regulates Sox 2 expression and glioblastoma stem cells. Oncogene 35: 4903-4913, 2016. 
41. Santarpia L, Calin GA, Adam L, Ye L, Fusco A, Giunti S, Thaller C, Paladini L, Zhang X, Jimenez C, et al: A miRNA signature associated with human metastatic medullary thyroid carcinoma. Endocr Relat Cancer 20: 809-823, 2013.

42. Hudson J, Duncavage E, Tamburrino A, Salerno P, Xi L, Raffeld M, Moley J and Chernock RD: Overexpression of miR-10a and miR-375 and downregulation of YAP1 in medullary thyroid carcinoma. Exp Mol Pathol 95: 62-67, 2013

43. Guan H, Liang W, Xie Z, Li H, Liu J, Liu L, Xiu L and Li Y: Down-regulation of miR-144 promotes thyroid cancer cell invasion by targeting ZEB1 and ZEB2. Endocrine 48: 566-574, 2015.

44. Shomron N: MicroRNAs and pharmacogenomics. Pharmacogenomics 11: 629-632, 2010.

45. Xia T, Liao Q, Jiang X, Shao Y, Xiao B, Xi Y and Guo J: Long noncoding RNA associated-competing endogenous RNAs in gastric cancer. Sci Rep 4: 6088, 2014.

46. Zhang HD, Jiang LH, Sun DW, Li J and Tang JH: MiR-139-5p: Promising biomarker for cancer. Tumour Biol 36: 1355-1365, 2015.

47. Kent OA, McCall MN, Cornish TC and Halushka MK: Lessons from miR-143/145: The importance of cell-type localization of miRNAs. Nucleic Acids Res 42: 7528-7538, 2014.

48. Kobayashi K, Imazu Y, Kawabata M and Shohmori T: Effect of long-term storage on monoamine metabolite levels in human cerebrospinal fluid. Acta Med Okayama 41: 179-181, 1987.

49. Jia X, Li N, Peng C, Deng Y, Wang J, Deng M, Lu M, Yin J, Zheng G, Liu H and He Z: miR-493 mediated DKK1 down-regulation confers proliferation, invasion and chemo-resistance in gastric cancer cells. Oncotarget 7: 7044-7054, 2016.

50. Tommerup $\mathrm{N}$ and Vissing $\mathrm{H}$ : Isolation and fine mapping of 16 novel human zinc finger-encoding cDNAs identify putative candidate genes for developmental and malignant disorders. Genomics 27: 259-264, 1995 .

51. de Celis JF and Barrio R: Regulation and function of Spalt proteins during animal development. Int J Dev Biol 53: 1385-1398, 2009.

52. May CD, Sphyris N, Evans KW, Werden SJ, Guo W and Mani SA: Epithelial-mesenchymal transition and cancer stem cells: A dangerously dynamic duo in breast cancer progression. Breast Cancer Res 13: 202, 2011.

53. Link LA, Howley BV, Hussey GS and Howe PH: PCBP1/HNRNP E1 protects chromosomal integrity by translational regulation of CDC27. Mol Cancer Res 14: 634-646, 2016.

54. Thornton BR, Ng TM, Matyskiela ME, Carroll CW, Morgan DO and Toczyski DP: An architectural map of the anaphase-promoting complex. Genes Dev 20: 449-460, 2006.

55. Lee SJ and Langhans SA: Anaphase-promoting complex/cyclosome protein Cdc27 is a target for curcumin-induced cell cycle arrest and apoptosis. BMC Cancer 12: 44, 2012.
56. Browning BL and Browning SR: Haplotypic analysis of wellcome trust case control consortium data. Hum Genet 123: 273-280, 2008

57. Huggins GS, Bacani CJ, Boltax J, Aikawa R and Leiden JM: Friend of GATA 2 physically interacts with chicken ovalbumin upstream promoter-TF2 (COUP-TF2) and COUP-TF3 and represses COUP-TF2-dependent activation of the atrial natriuretic factor promoter. J Biol Chem 276: 28029-28036, 2001.

58. Song HM, Luo Y, Li DF, Wei CK, Hua KY, Song JL, Xu H, Maskey N and Fang L: MicroRNA-96 plays an oncogenic role by targeting FOXO1 and regulating $\mathrm{AKT} / \mathrm{FOXO1/Bim} \mathrm{pathway}$ in papillary thyroid carcinoma cells. Int J Clin Exp Pathol 8: 9889-9900, 2015.

59. Chruścik A and Lam AK: Clinical pathological impacts of microRNAs in papillary thyroid carcinoma: A crucial review. Exp Mol Pathol 99: 393-398, 2015.

60. Nicholson KM and Anderson NG: The protein kinase B/Akt signalling pathway in human malignancy. Cell Signal 14: 381-395, 2002.

61. Xue $\mathrm{G}$ and Hemmings BA: PKB/Akt-dependent regulation of cell motility. J Natl Cancer Inst 105: 393-404, 2013.

62. Osaki M, Oshimura M and Ito H: PI3K-Akt pathway: Its functions and alterations in human cancer. Apoptosis 9: 667-676, 2004.

63. Manzella L, Stella S, Pennisi MS, Tirrò E, Massimino M, Romano C, Puma A, Tavarelli M and Vigneri P: New insights in thyroid cancer and p53 family proteins. Int J Mol Sci 18: pii: E1325, 2017.

64. Zhu X, Zhao L, Park JW, Willingham MC and Cheng SY: Synergistic signaling of KRAS and thyroid hormone receptor $\beta$ mutants promotes undifferentiated thyroid cancer through MYC up-regulation. Neoplasia 16: 757-769, 2014.

65. Kataki A, Sotirianakos S, Memos N, Karayiannis M, Messaris E, Leandros E, Manouras A and Androulakis G: P53 and C-FOS overexpression in patients with thyroid cancer: An immunohistochemical study. Neoplasma 50: 26-30, 2003.

66. Aliyev A, Soundararajan S, Bucak E, Gupta M, Hatipoglu B, Nasr C, Siperstein A and Berber E: The utility of peripheral thyrotropin receptor mRNA in the management of differentiated thyroid cancer. Surgery 158: 1089-1094, 2015.

67. Huang FJ, Zhou XY, Ye L, Fei XC, Wang S, Wang W and Ning G: Follicular thyroid carcinoma but not adenoma recruits tumor-associated macrophages by releasing CCL15. BMC Cancer 16: 98, 2016. 